\title{
All about arsenic
}

\author{
If ever there was an element that epitomizes the notion that chemicals might be good or bad depending \\ on their use, arsenic must be it. Katherine Haxton explains why.
}

E lemental arsenic was first identified in 1649 , but its minerals have been known since Aristotle first described them in the fourth century BC. Arsenic compounds are perhaps some of the most notorious chemicals, particularly arsenic (III) oxide $\left(\mathrm{As}_{2} \mathrm{O}_{3}\right)$, which has often somewhat confusingly - simply been called 'arsenic'. This substance, also referred to as poudre de succession or 'inheritance powder' in seventeenth-century France, has been the main protagonist in many high-profile murders throughout history.

In contrast, many Victorians were fascinated by arsenic for less nefarious purposes, and frequently self-medicated with it - even using it as an aphrodisiac. Charles Darwin was said to use it to treat eczema. Arsenic compounds were also used to produce a beautiful green dye for wallpaper and other goods. Once again, however, the darker side of this element would often come to the fore, when a fungus present in damp houses converted the dye into volatile arsenic compounds and resulted in many cases of poisoning. This route of exposure to arsenic was recently implicated in the death of Napoleon Bonaparte, exiled on St Helena in the South Atlantic'.

Organoarsenic compounds were first prepared by Louis-Claude Cadet de Gassicourt in the 1750s. Their precise chemical composition was not immediately known - a trait of arsenic chemistry that would continue throughout the twentieth century - but a fuming liquid with a strong garlic odour was produced. In the midnineteenth century, Robert Wilhelm Bunsen took up the challenge of identifying Cadet's fuming liquid, formed through the reaction of $\mathrm{As}_{2} \mathrm{O}_{3}$ and potassium acetate. The product, tetramethyldiarsane or 'cacodyl', a name fittingly derived from the Greek word kakodyl meaning 'stinking', was determined by elemental analysis with input from Berzelius ${ }^{2}$. This was the beginning of organoarsenic chemistry and a wide variety of cyclic and linear compounds are known today.

A key organoarsenic compound - Salvarsan (also known as arsphenamine) - developed by Paul Ehrlich was both the first treatment for syphilis and the first known chemotherapy agent. It was Ehrlich who coined the phrase 'magic bullets' to describe molecules that would rid organisms of parasites. Individuals suffering from latestage syphilis were unresponsive to Salvarsan, and treatments were difficult because the drug had to be protected from the air. Inspired by the positive results seen in patients in the early stages of the disease, however, Ehrlich spent considerable time developing better handling procedures and ultimately a derivative that had fewer side effects and was easier to administer. Salvarsan was later identified as a mixture of cyclic structures with As-As bonds ${ }^{3}$.

Arsenic is the twentieth most abundant element on earth and is fairly ubiquitous in living systems - consequently arsenic poisoning poses a real threat to many people around the world. In countries such as Bangladesh, wells are frequently dug to provide clean, fresh drinking water, eliminating the need to draw water from stagnant ponds rife with disease-causing microbes. Unfortunately the nature of the underlying geology in many areas means that the ground water is often contaminated with arsenic, and poisoning symptoms are becoming commonplace - an estimated 70 million people in Bangladesh have been exposed to high levels of arsenic.

Arsenic undergoes a range of chemical reactions in the environment and this speciation makes it difficult to remediate. Moreover, arsenic contamination does not always come purely from natural sources - arsenic compounds have been used as feed additives for livestock, and as insecticides, providing other routes through which the element may enter living systems. A brief literature survey reveals that most of the hits for arsenic are concerned with the health implications of involuntary consumption, rather than the elegance of organoarsenic chemistry.

In early 2011, the discovery of bacteria that could survive in conditions high in arsenic caused quite a stir. Taken from Mono Lake in California, initial studies suggested that arsenic might replace phosphorus in the DNA of the bacteria, resulting in a high tolerance to the element ${ }^{4}$. This was widely debated, with many scientists arguing that arsenic esters are simply too labile to result in a stable analogue of DNA.

This twenty-first-century discovery may offer some hints regarding the nineteenth-century arsenic eaters of Styria (southeast Austria), where arsenic was consumed to freshen the complexion. Reports of people consuming large $(300 \mathrm{mg}$ ) quantities of $\mathrm{As}_{2} \mathrm{O}_{3}$ - a substance that is typically fatal at doses above $65 \mathrm{mg}$ - without deadly consequences prompted theories that organisms may become habituated to the poison, although later studies refuted this. Whatever the eventual consensus on the Mono Lake bacteria ${ }^{5}$, arsenic continues to be one of the most fascinating elements, a would-be saviour and deadly assassin.

KATHERINE HAXTON is in the School of Physical and Geographical Sciences, Keele University, Keele ST5 5BG, UK.

e-mail:k.j.haxton@chem.keele.ac.uk

\section{References}

1. Kintz, P. et al. Forensic Sci. Int. 170, 204-206 (2007).

2. Seyferth, D. Organometallics 20, 1488-1498 (2001).

3. Lloyd, N. C. Angew. Chem. Int. Ed. 44, 941-944 (2005)

4. Wolfe-Simon, F. et al. Science 332, 1163-1166 (2011).

5. Alberts, B. Science 332, 1149 (2011).

10000000

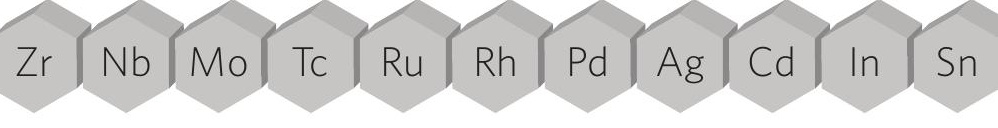

